
[ARTICLE 9,-EXTRACTED FROM THE BULLETIN OF THE U. S. FISH COMMISSION FuR 1895. Pages 369 to 378 . Plate 72.]

\section{CONTRIBUTIONS}

\section{APR $21{ }^{1896}$}

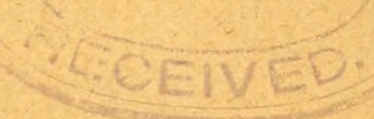

TOWARD THE

\section{Improvement of the Culture of Salmonoids and Crawfish in smaller water courses.}

KAFI, WOZFILISA=IGIAI.

WASHINGTON:

GOVERNMENT PRINTING OFFICE.

1896. 



\section{CONTRIBUTIONS}

TOWARD THE

\section{Improvement of the Culture of Salmonoids and Crawfish in smaller water courses.}

IX ARL WOZFLKA=IGLAU. 1

WASHINGTON: GOVER N M NT PRINTING OFFICF. 1896. 
SH15l
WJ 


\title{
9.-CONTRIBUTIONS TOWARD THE IMPROVEMENT OF THE CULTURE OF SALMONOIDS AND CRAWFISH IN SMALLER WATER-COURSES.*
}

\author{
BY KARL WOZELKA-IGLAU.
}

[From "Deutsche Landwirthschaftliche Presse," Nos. 28 and 3I ; Berlin, April 6 and 17, I895.]

The present management of our smaller water-courses, of streams of different size, but containing a quantity of water sufficient at least for the steady working of a flourmill or sawmill, leaves a great deal to be desired in the matter of fish or crawfish culture. We can hardly speak of the cultivation of these water-courses (frequently the finest and most suitable streams for trout) in the proper sense of the word. In most cases they are left to themselves; and ouly between the different falls are fish and crawfish-if the stream contains enough to make the labor remunerative-caught with nets, reels, etc.; occasionally also by laying the milldam dry. In very few eases is the stream stocked with young fish or spawn or mother erawfish, and then only to maintain the actual supply of fish or erawfish.

These natural streams ean never, or at best only partially, be laid dry; fishing can not be carried on systematically, and a proper management is consequently out of the question. We therefore find in those streams which have a large supply of fish, besides crawfish of every age, predaceous fish and other fish of many varieties and different sizes. Under such circumstances the stock of fish and crawfish can never be fully developed, because a coustant war is going on between the different inhabitants of these streams, with a consequent reduction of numbers. The water could frequently contain a much larger quantity of fish or crawfish if they were only allowed to increase in number. Cultivated fish, in the full sense of the term, are not known in these waters. The spawn deposited by the more valuable fish (trout, grayling, etc.) is partly devoured by crawfish and partly destroyed by bullheads, gudgeons, etc. Natural oceurrences (floods, drought, heavy ice, etc.) also contribute their share toward diminishing the spawn. Artificial impregnation, hatching, and the careful raising of the young fish and crawfish will be thoroughly appreciated if we bear in mind that of the spawn or young erawfish deposited in natural waters hardly 5 per cent are developed into full-grown fish or crawfish. If young fish or crawfish are placed with larger animals of their own kind, it may be assumed with absolute certainty that in a very short time 70 to 80 per cent will be destroyed. What is the use, therefore, of careful cultivation under such circumstances?

* Beitrag zur Hebung der Salmoniden- und Krebszucht in kleineren Wassergerinnen.-H. Jacobson, translator.

NoTE.-This article is presented in the hope that it may afford suggestions for the utilization of some of the waters of this country, even though all the conditions mentioned as present in the streams of Bohemia may not exist in those of the United States. 
If the culture of fish or crawfish is to succeed in streams it is necessary-

(a) That there should be a possibility of laying these streams entirely dry at times and removing all fish.

(b) Fish of the same kind which are to be cultivated should be all of the same age. If several kinds of fish are cultivated in one and the same water, they must moreover be equally developed. Fish and crawfish, even if they are of the same age, must under no condition be raised in one and the same water. Trout, e. g., will, under suitable conditions, weigh 300 to 400 grams [about 10 to $13 \frac{1}{2}$ ounces] after the completed second year, and at that age fetch the best price in the market. The crawfish, however, needs from five to six years in order to find buyers at a weight of 50 grams [21 $\frac{1}{3}$ ounces]. The objection to stocking water with young trout and crawfish of the same age is not so much the inconvenience caused by the circumstance that fishing will have to be carried on at two different times, as the vast difference in the growth of these two animals. If the yearling trout weighing about 100 to 150 grams $\left[3 \frac{1}{3}\right.$ to 5 ounces] do not entirely destroy the little erawfish of the same age, but weighing only 1 to 2 grams during the first year, the 2 -year-old trout, now weighing about

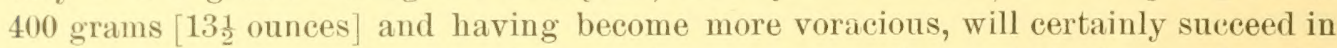
destroying all the young crawfish which now have only reached the weight of 4 grams.

(c) Finally, eare should be taken to furnish a constant supply of nutritious natural food.

As it will be far easier to introduce a well-regulated remunerative culture of fish and erawfish in small streams which are generally fed from springs, and consequently have pure and healthy water at all times, than in rivers whose water has been polluted by refuse from factories, more attention should be given to this matter.

In order to derive the greatest possible benefit from the water of a stream and to gain as many separate inclosures as possible for the proper rotation necessary in well-regulated fish-culture, ditches of varying breadth must be dug on both sides of the stream 70 to 90 centimeters [ $2 \frac{1}{2}$ to $3 \frac{1}{2}$ inches] deep and 50 to 100 meters [ $16 \frac{1}{4}$ to $32 \frac{1}{2}$ feet] in length. With these ditehes (fig. 7) puddles, and in fact larger or smaller depressions of the ground, may be advantageously united, and wherever the ground is favorable small independent ponds may be constructed and fed from the water of the stream.

In order that the water of the stream within the limits of the establishment may at any time be withdrawn from the different ditches (the smaller ponds, as well as from the channels through which the water flows in and out) so that all these watercourses or ponds may be laid dry and all the fish removed therefrom, they are arranged in such a manuer that the bottoms form geometrically inclined planes (every valley of a stream will have sufficient fall), or at least do not deviate very much from such planes. The bottoms of the smaller ponds need not always have the same inclination as the bottoms of the ditches, etc., but may be dug out all the deeper, in proportion as their outflow channels are dug out deeper, supposing, of course, that there is sufficient fall. It is self-evident that the bottoms of the smaller ponds must always be a little higher than the upper part of the bottoms of their drains, in order that these small basins of water ean be laid thoroughly dry at any time. If the water is led into these basins from a considerable height, and consequently with a smaller fall, they may be dug out deeper and their area may be likewise enlarged. All this work, however-which will be more fully described farther on-must be preceded by 
the construction of a contrivance (a description of which will be given) which renders it possible to do all the digging, etc., after the bed of the stream has been laid dry, without any interference by the water.

The first thing to be done is to give to the portion of the stream concerned a bottom as evenly inclined as possible, by leveling sand banks, removing stomes, and filling holes, so that there are no puddles in which fish or crawfish may remain when the stream is fished clean. If the mouths of the ditches are placed at the same height as the bottom of the stream after that has been regulated, the fall of the short stream will distribute itself throughout the longer ditches and channels, and, consequently, that portion of the water which enters the ditches and channels will flow much less rapidly than the water in the stream itself. Although it is not necessary that the bottoms of all the ponds should present the same geometrical inclination, it is essential that the bottom of each pond or inclosure from the place where the water enters to the place where it flows out into the stream should form an inclined plane.

In order to distribute the disposable water of a stream as evenly as possible throughout the ditches, their ponds or puddles-and in the bed of the stream itself, the entrance and outflow of two ditches, which are of course close together-should invariably be placed about the middle of the third opposite ditch. Into each ditch one-half of the disposable water of the stream is led, and into each pond channel onethird. In order that the water may, by partial damming, flow better into the ditches and channels, and to enable the cultivator to measure out to each inclosure a certain quantity of water, a board should be placed below the mouth of every ditch and channel. These boards (figs. 2 and 3), which are of varying length and breadth, to suit the different circumstances, have an oval opening in the lower central portion, so that the fish (and also the crawfish) have a chance to go up the stream.

If these boards are fastened so deep to two strong poles firmly rammed in the bottom that the lower edge of the oval opening is on a level with the bottom of the stream or of the ditches, the various inclosures can always be laid dry and all the fish removed therefrom, even if the boards are left standing, because the water, with its fish, has a sufficient outflow through the openings. The size of the opening depends on the quantity of water which can be counted on. Under no circumstances must the opening be larger than the cross section of the water flowing through the water-course, for otherwise there could be no damming, and no small waterfalls could be formed. The rushing of the water over the board in the form of a small waterfall is an advantage, not only because the water thereby becomes more impregnated with oxygen, and therefore more wholesome, but also because the trout loves such waterfalls and whirlpools. Such boards are also placed in other parts of the stream and the ditches, and, in fact, wherever the raising or damming of the water appears desirable for the purpose of making the sheet of water deeper or broader, or making the current slower. By means of these boards smaller water-courses, and even streams with higher banks and a stronger fall, will be rendered suitable for fish-eulture.

The entrance and outflow of all the ditches are dug out as narrow as possible and as nearly of the same breadth as practicable. This is necessary in order that the ditehes can be more easily and better shut off from the stream and the fish be removed therefrom, and in order that contrivances for shutting off having the same size may be used in all. Each individual ditch is shut off a little back of the entrance (above) and a little above its outflow (below), and thus forms an independent inclosure. In the same way the small channel through which the water flows in and out of each 
independent pond is shut off from the stream, and each pond from its feeder by the same contrivance (instead of a fish-rake). It is best to use for this purpose strong galvanized-wire gratings (which can, at a reasonable price, and in all sizes and strengths and width of meshes, be obtained in all wire factories). These gratings must be a little larger than the ditches which are to be shut off (fig. 4), so that they can be let into the edges and the bottom of the ditch from 8 to 10 centimeters [abcut 3 to $3 \frac{1}{2}$ inches]. It is well known that salmon, owing to their strong migratory tendency, will leap over impediments found in their way, and will attempt to escape from inclosed waters.

In order to lay a ditch dry at any time and remove the fish therefrom, without interrupting the flow of the water in the stream and in the other ditches, a larger board or floodgate (fig. 5), having the form of the profile of the ditch, is placed above, near the entrance to the ditch, a little in front of the grating mentioned above. This contrivance consists of grooved boards with cross ledges and a handle, with sharp edges below; and on the sides it is let into the edges and bottom of the ditch. The consequence of this interruption of the eurrent in the highest part of the diteh will be that the water, and with it the fish (crawfish can be picked off the bottom of the stream when it is laid dry), will slowly flow farther down, and all the fish can in this way be conveniently caught just in front of the lower grating of any ditch or inclosure which is treated in this manner. The water of the stream will only be dammed up very little in the lower part of the ditch, and only form a small puddle back of the lower grating, where the fish can be easily taken out. It can, of course, not be avoided that a few fish are found even back of the boards with the oval holes.

In order that the above-described work may be done in dry ground, that the establishmentmay be protected against floods, and that all the fish may at any time be taken from the stream itself (which is to be cultivated independently of the ditches and ponds), an arrangement must be made in the stream above the establishment which renders it possible to shut off the water there, either in part or entirely, and lead it into one or two specially constructed ditches. This arrangement consists of a stronger floodgate (fig. 6 ), with a higher and well-fitting wing. The two special ditches referred to above begin a short distance above the floodgate, are carried along the two sides of the establishment and empty their water into the stream below the establishment. In order to make a flood possible in longer ditches (without giving them a stronger fall, and therefore making them shorter), they are (as shown in fig. 7) furnished here and there with short steps paved with stones. If it is possible to cultivate grass in the flat ditehes which are only temporarily used, it will not be necessary to construct these stone steps, and some little advantage may be derived from the grass, which may be used as fodder for cattle.

The wing of the floodgate of the stream is, during the season of cultivation, only raised high enough to allow the normal quantity of water to enter the establishment, and may therefore also remain open during periods of high water. In order to prevent, when the water is at its normal height, part of the water needed in the establishment from entering the two flood ditches, and thus carrying it away, a strong and tolerably high board is rammed firmly in each ditch near its entrance. The height of these two boards is regulated by the normal depth of the water. If the wing of the floodgate is opened wide enough for the water to wet its lower edge, the two boards in the flood ditches are placed at such a height that at the same depth of water their upper edges are laved by the water. In fig. 6 we see this 


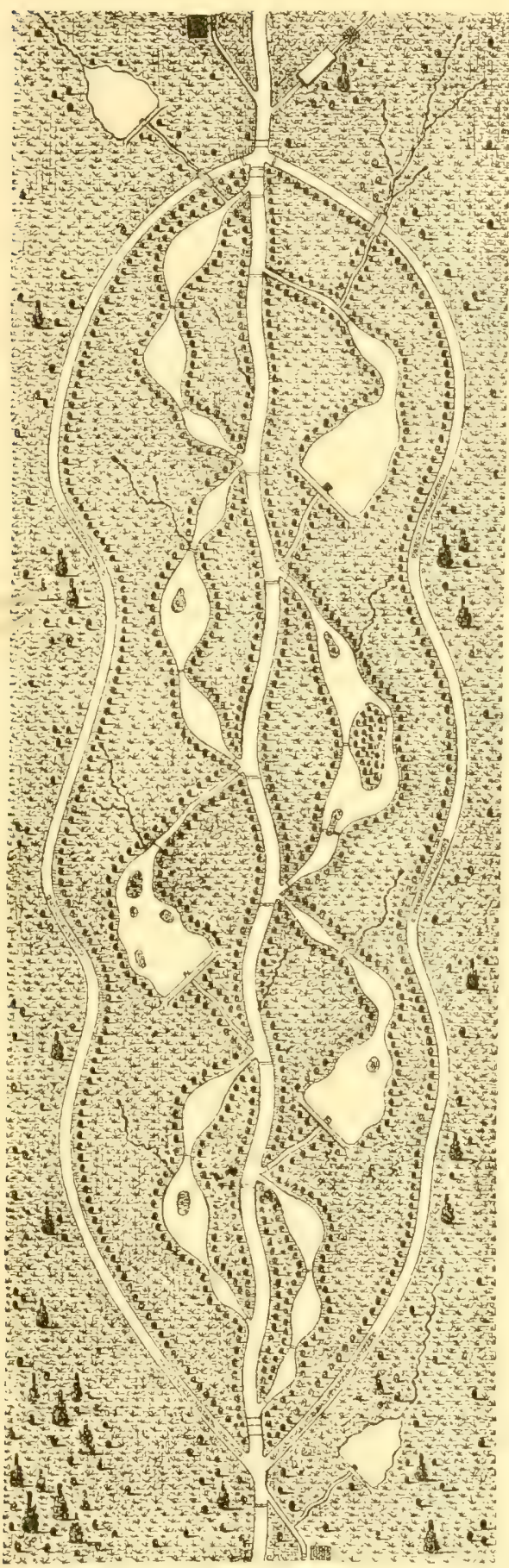

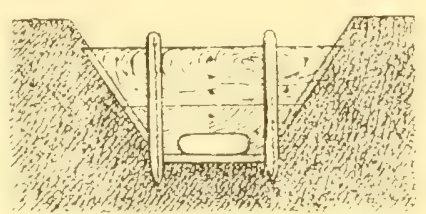

Fig. 2.-Sluice with fish runs (front).

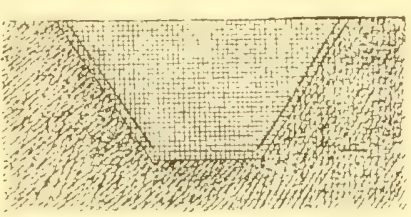

Fig. 4.- Permanent fish glatıng.

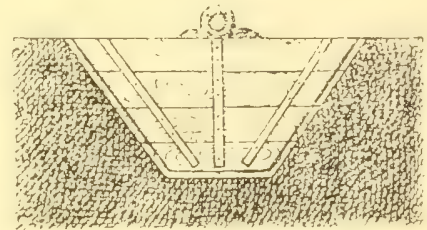

Fio 5. Temporary wooden dam.

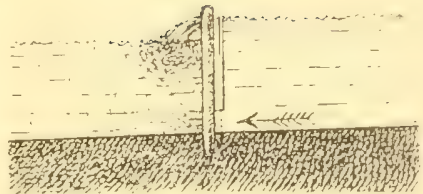

Fle 3 Sluice with fish runs (side)

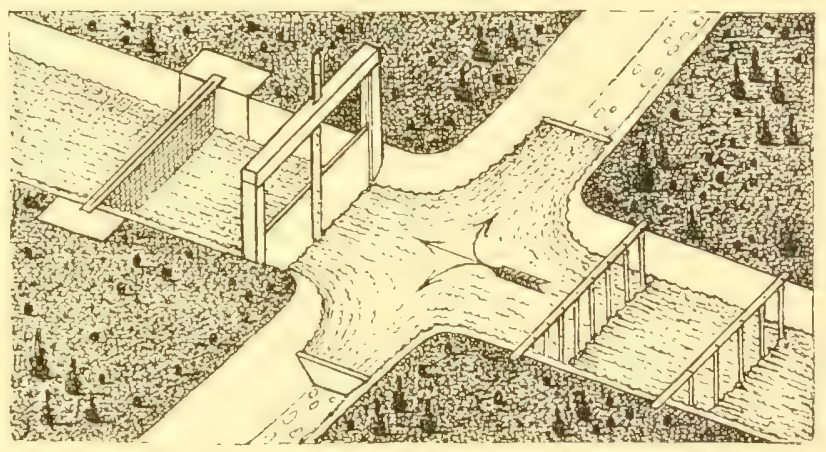

Fig. 6 - Head of firm water gate, grating and side escapes.
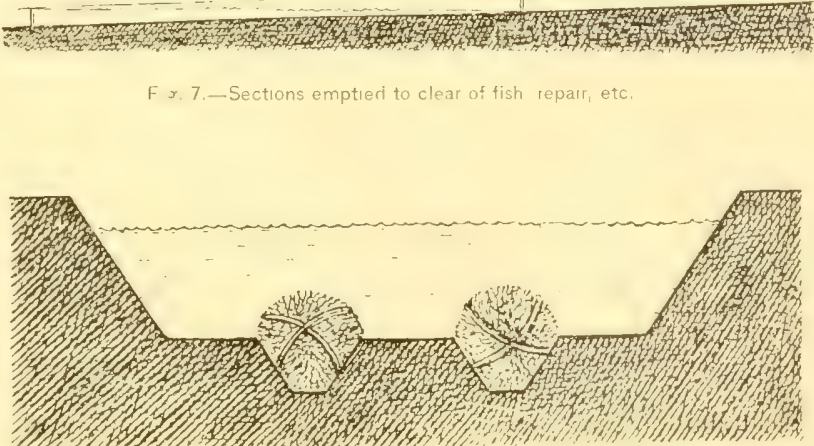

process illustrated. If there is high water, the pressure of the water causes a little more to enter the establishment than during its normal conrse. but the remainder of the water, which would be detrimental to the establishment, is thrown back by the wing of the floodgate, and is led off over the two above-mentioned boards through the flood ditches. It is, of course, understood that if high water is expected, the wing of the floodgate is placed a little lower, if during the period of high water no more than the normal quantity of water is to be used in the establishment. By these precautionary measures the establishment is therefore at all times sufticiently protected against high water. To prevent fish or crawfish from escaping from the inclosures during the season of cultivation, and to prevent predaceous fish from entering, a thick galvanized-wire grating is placed in the stream both below (back of the outtlow of the iast ditch) and above (below the Hoodgate). These wire gratings are fastened in frames and set in grooved stone walls (fig. 6).

To prevent these wire gratings from being pushed out of position by "floating pieces of wood, branches, leaves, and other objects which would interfere with the current, two primitive wooden rakes are placed in the water-course, both above the two flood ditches, at a distance of 2 to 3 meters $\left[6 \frac{1}{2}\right.$ to $9 \frac{1}{3}$ feet] from each other, and below, just in front of the lower grating. The teeth of each of the two front rakes (fig. 6) are at quite a distance from each other, so as to catch only larger objects, while the teeth of the two other rakes are choser together, so as to stop smaller objects which have passed the first rake. By this arrangement the two gratings will never become choked up and the water can flow through freely.

Whenever fish are to be taken out of that portion of the stream which is inclosed in the establishment, the water in all the ditches and ponds must be shut off. This object is best attained by the two damming boards (fig. 5) described above. Boards are at the same time placed in all the ditches in front of the lower gratings, and, if necessary, in the ditches themselves, invariably at eveu distances. It is, of course, understood that this measure is taken in one division after the other, and not in all at the same time. It', in construeting the ditches, care is taken that the damming is done in narrow passages and just in front of places where the ditches widen out, or where there are puddles or ponds, a large quantity of water can be shut off, even without using very broad boards. The longer a diteh is, and the stronger its fall, all the more boards will be needed for shutting oti the water. While, e.g., a ditch with a strong fall will need three to five boards, the same object-viz, the shutting off of the waterwill be attained in an equally long diteh, but with less fall, by two to three boards.

All that is needed is that the water in each division (see fig. $\overline{7}$ ) should only be dammed up to the foot of the higher board. There would be no harm even if in each section the upper part of the bottom were kept dry for a leugth of 1 to 2 meters [3.28 to 6.56 feet]. In the lower part of each section the water will, in the beginuing, before it reaches its proper level, overflow the board a little both at the top and at the sides. It need not be feared that any fish will escape.

To better illustrate the use of the damming boards, we will give a practical example: A ditch 60 meters [19.6 feet] long, and 70 centimeters [2.4 inches] deep, will, with a total fall of 190 centimeters [7.t inches] only need three damming boards placed at equal distances from each other. With three boards and a ditch 70 centimeters deep, however, a fall of 210 centimeters [ 8 inches] could be used. But as we need an entire height of boards of 190 centimeters [7.t inches] in order to shut oft' the water in the ditch, the entire fall might he 20 centimeter's [0.7s inchl ] nowe, and still three boards would suffice. 
After the water, with its fish and crawfish, has been shut off in all the ditches and chamnels, the floodgate above the establishment is closed tight. The consequence is that the water is dammed up in front of the floodgate, flows back, and takes its

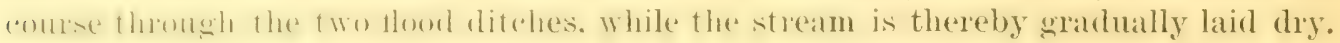
In front of the lower grating the fish can then be easily caught.

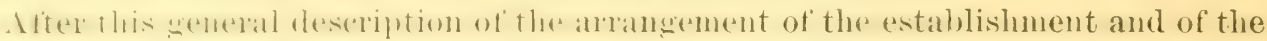
use of its difierent portions, some important points remain to be spoken of. These are: 1 ) The stanting of the "ultivation operations: $(2)$ the selection of the tish: (3) the cultivation itself; (4) the raising and feeding of the fish or craw fish.

In regard to these four points it is important to observe the following: After all the digging has been dome in dry soil, alter the two large wire gratings for shutting ofl the stream. the smaller gratings for shutting off the ditches and rhamels, the ralies inside and ontside of the establishment, and the two boards in the flood ditehes, hal all been plated in pusition, and after the pits fir producing food (to be described farther on) have been dug, and the posts have been rammed in the ground wherever there are to he damming hoards, the floodgate is oprened wide enough to admit into the wablishnent the normal yuantity of water, and no more. Tot till then, and when the water is allealy entering the estahlishment, the sime of the oval openings of the damming boards is determined, which are now firmly fixed (screwed) to the posts.

As the water of small streams fed by spriugs is colder in summer and warmer in "inter than staglnant watel, these streams will ralely freeze cotirely, and the eulture of fish may therefore be carried on uninterruptedly. Under these circumstances the cultivation of the various salmonoids (which are always in demand) and of the ("law fish is to he recommenderl. Of salmonoids several well-tried domestic: and foreign species are at our disposil. Among the different varieties of trout preference must

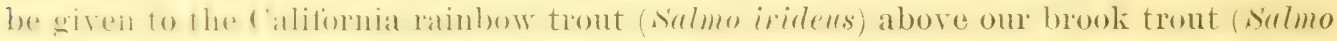
fario), because it grows much quicker, makes an excellent article of food, aud is not very choice in the matter of its food. Among the rest, the equally rapidly growing cross breeds between the brook trout and the salmon tront (Salmo lacustris), of the brook tront and the salmon (Sulmo salar), of the brook trout and the char or "siilbling" (Salmo salvelinus), of our brook trout and the imported American brook trout (Salvelinus fontinalis), and of the German char and the American brook tront,

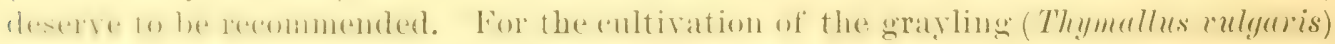
these smaller water-courses are not so well adapted. If erawfish are to be cultivated

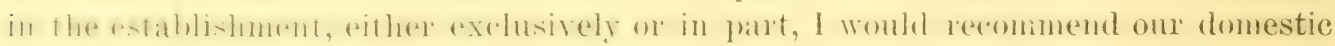
central European brook crawfish (Astacus fluviatilis), which is considered a great delicacy. The larger crawfish of Carniola, Galicia, and liussia would, owing to the changed conditions, soon degenerate, and it is very questionable whether their cultivation wonld be possible.

The stocking of the various ditches with young fish or young craw fish, invariably of the same age aud the same rapid growth, may be done in different ways. All the sections may be used either entirely for fish-culture or for crawfish-culture, or some of the sections for one and some for the other. Cultivation following the principle of rotation is to be highly recommended. In the culture of salmonoids, e. g., if the tish are to be nsed when 2 years old, one-half of the ditches might be stocked in spring, while in the other half the fish would be canght in the autumn of each year. If the fish are to reach the age of 3 years, only one-third part of the ditches will be fished and stocked anew every year. If erawfish are to be used, when 5 years old 
there would be fishing every year in one-tifth part of the ditches, and one-fifth would be stocked anew, etc. In order, e. g., to introduce a two years' culture, either one-half only of the ditches would be stocked during the first year': or all the ditehes are stocked during the first year, but the fish in half of them are allowed to grow one year older. while in the other half they are caught after the completed first year. In crawfish-culture those ditches which in the beginning are not to be stocked with crawfish may during that time be used for fish-culture. When the fishing in a rough or rapid stream is dificult, such stream should be used for crawfish-culture, so that there need not be any fishing except at longer intervals (five to six years). There need not, however, be any fishing whatever in the stream if it is used as a reservoir for crawfish which are ready for the market (which can at all times be eaught with reets, ete.). or it it is utilized for the steady production of natural food for the fish.

In the small ponds belonging to the establishment, whose feeding chammels may very advantageously be used for the exclusive production of live natural fish food, which is thus continumsly furnished to the fish in the ponds. the culture of salmonoids or crawtish (or. if the water is softer and warmer. the culture of earl) may be arried on. The channels through which the water flows ont of the ponds may be very suitably employed for crawfish-enlture. In exclusive or partial salmonoid-culture, however, one to three of the smaller ponds, according to their size, should be used for the production of young food-tish, and in exelusive or partial craw fish-culture one to two of these sheets of water should be reserved for the pairing of crawfish. The ponds not used for this purpose, the channels through which their water flows off, and possibly also the stream itself, may be cultivated either inderendently, according to a system of rotation applying ouly to these waters, or in common with the ditehes.

The fish-culturist will do well to raise his own propagating fish. The artificial impregnation of roe is a rather wearisome process, as suitable spawners have to be

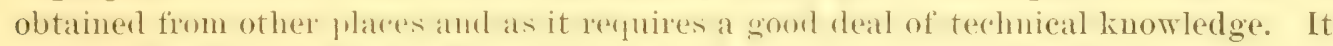
is, therefore, better for the fish-eniturist to obtain embryonated roe from some wellknown establishment and only attend to the further development of this roe. $\mathrm{He}$ themeby gains this alvantage, that the young fish may he hatched in the same water in which they are to be raised. We know it for a fact that the brook trout can be raised even in soft waters, and the rainbow tront even in muddy ponds, if their roe has been hatcher in the same water.

It is likewise somewhat difficult to obtain suitable young fish. In a small fishtank, with water steadily flowing into it, which every establishment for raising salmonoids or crawfish should possess, it will be very easy to place apparatus for hatching fish. A walled basin, correspomling to the size of the establishment, from which the water can be let oft, which is in the immeriate proximity of the hatchery and must be supplied with a constant strean of luming water. may receive, in fishculture, the young fish which have slipped out of the eggs in the hatching apparatus. and in crawfish-eulture the female crawtish with egges which have been brought from the breeding-ponds. It should be mentioned that the female craw fish, soon after the young erawtish have been hatched, should be removed to the breedingponds where the males have been left, as they are very apt to attack and destroy their own offspring. Althongh the above-described basin is not absolutely necessing, becanse the yonug tish and the female erawtish may also be placed directly in the 


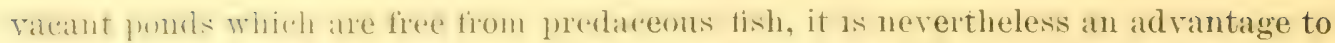

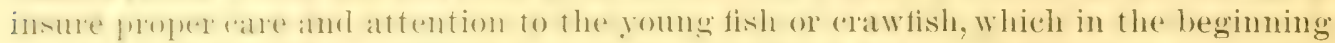

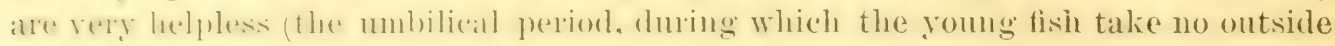
food, lasts with the salmonoids, e. g., four to six weeks), and to bring them sooner to a state of independence by placing them in the large basin covered with sand and gravel and amply supplied with aquatic plants, giving them plenty of good food (live crustaceans, maggots, worms, ete., to the fish; fish, frogs, meat, crustaceans, ete., chopped fine, to the crawfish).

The limited space at my disposal does not permit me to deseribe here an establishment for raising shrimps (which in the exclusive culture of salmonoids may take the place of the basin), by means of which the young fish will grow strong very rapirby though the coutinuous mutritious natmal food which is furnished to them. I would refer the reader to my pamphlet on the subject, entitled, Nenes Fisch- und kiels.suchtrerfithen mit Weidenkultur verbunden und anf die natiuliche Fiitterung hatsirend new method of raising tish and clawfish in connection with the rultivation of willows, and based on the system of natural food).

It will be found an advantage to stock the waters with large and strong fish or

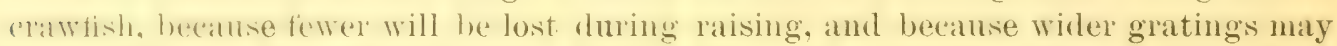
be used for shutting off the ditches. If the basin can be properly secured, it may, during antumn and winter, when there is no other use for it, be employed as a reservoir for fish or erawfish.

The number of tish or "rawtish to be placed in the water of the inclosures depeuds entirely on the food conditions of the water. It may be said, however, that 20 to 30

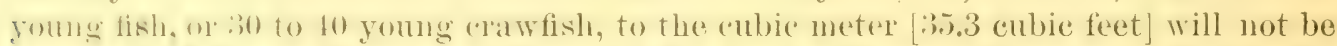
toc many if the pombloms ane favorable for constantly smplying ample food as the fish or crawfish grow up and need more food. A cubic meter of water in a trout

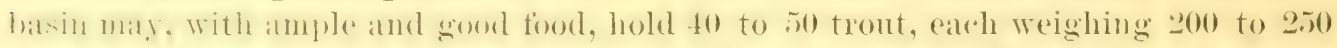
grams $\left[6 \frac{2}{3}\right.$ to $8_{3}$ ounces] and reaching even a heavier weight. I would warn against overstocking a sheet of water, because the food would then hardly be sufficient to properly support the fish.

As regards the feeding of fish, ete, nature furnishes an exceedingly weleome aid. The large rivel shrimp) (fommurus fossurum) is always foumd in enormons quantities in clear rumning water. In the lind of establishment described by me, the bottom "HIrent of the watre "ansed ly the holes in the damming boards proves exreedingly firveable to these shrimps, which form the most desirable food for trout and craw fish.

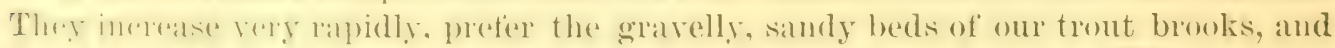

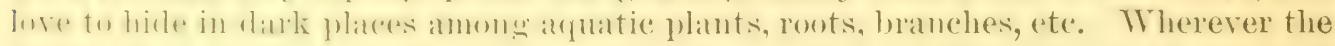
bottom does not consist of sand or gravel this should only be introduced in small quantities, because the trout and crawfish like such a bottom as well as the shrimp. While the large tront in streams where it prevails will not sufter any other fish (whitings, minnows, gudgeon, bullheads, ete.) or erawfish to exist for any length of time, it will not succeed in exterminating the shrimp. But, on the other hand, the small trout will lose a great deal of its principal food if the above-mentioned fish or erawfish increase very rapidly. It will therefore be best to banish such fish or crawfish entirely from the trout waters.

In carp-raising ponds predaceons fish (pike, eel, perch, ete.,) are placed in order

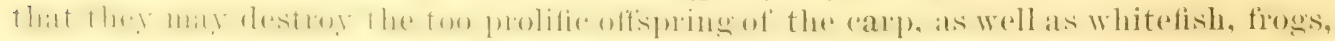
ote., which would deprive the earp of a good deal of their food. As the shrimp is an 
exceedingly important article of food in the culture of salmonoids and crawfish, we must seek to encourage its development by supplying artificial hiding-places and also by feeding it. Especially in the early stages of the establishment, when the bottom and sides of the ponds and ditches are not yet covered with plants, it will be well to supply such hiding-places (e g., by transferring or planting aquatic plants). Such artificial hiding-places for the shrimps may also be provided in the ditches and in the stream by digging round holes with an upper diameter of 40 to 50 centimeters (1.5 to 1.9 inches) and a depth of 20 to 25 centimeters ( 0.78 to 0.88 inches), at an angle of 45 degrees toward the bank. These holes should be dug at distances of about 5 meters (16 feet), and wherever the ditches widen out they may be seattered more frequently. Such holes may also be dug in the channels through which the water flows in and out of the basin.

In these holes are placed branches deprived of their leaves, which (by means of pine roots, willow branches, etc.) have been loosely bound together and formed into a sort of ball, and which may project over the middle of the hole and its edges, stones being put in the inside of these balls to keep them in position. In fig. 8 we see in a broad part of a ditch the cross section of two such shrimp holes with the balls of branches inserted. The fish and crawfish, when in search of food, can not, on account of their size, enter these holes, and the shrimps find sufficient protection in them, and can therefore undisturbedly increase in these hiding places. This arrangement, moreover, permits a very rapid and simple method of feeding the shrimps, as it will be sufficient to throw on these branches from time to time a handful of coarse meat-meal, chopped-up fish, frogs, mussels, meat, maggots, etc. It has the further advantage that whenever the fish are taken out of the ditches, ponds, etc., the main portion of the shrimps will remain alive, because they can retire to their holes, in which some water will always remain while the ditches are slowly laid dry. To eatch a large number of shrimps at any time, it will be sufficient to pull out the branches or balls of branches and shake them over a piece of cloth. In newly constructed inclosures the shrimps must, of course, be introduced in larger quantities and be evenly distributed.

The fish or crawfish should not be placed in the water until the shrimps have increased considerably and have occupied their holes. It might also be recommended to give these small crustaceans a short period of protection after each fishing season. The cultivator of salmonoids and crawfish possesses in these holes reliable, constant, and abundaut sources of food for his fish. In the more stagnant water of the ponds shrimp-culture will not be so successful, but even there the above-described method of promoting the increase of other crustaceans in these ponds will benefit the entire cultivation.

The supply of natural food for fish, etc., may be still further increased if willows are planted close together, each plantation extending from 2 to $2 \frac{1}{2}$ meters [ 6.8 to 8.5 feet] on both sides of the inclosures. Thereby many insects, especially many different kinds of gnats and flies, are attracted, which, owing to the sheltered condition of the water, deposit their eggs therein. In order to make this more convenient for them, it is recommended to fix widely spreading branches at certain distances in the banks in such a manner as to let them rest on the surface of the water. The larvæ of these insects make an excellent food for fish. The willows, moreover, will furnish a habitation for a large number of different kinds of caterpillars, beetles, spiders, bugs, ete., which often drop into the water and very considerably increase the food supply for the fish. 
In order to furnish the fish with thousands of these insects, it will be sufficient to brush the narrow strip of willows with a small board attached to a light pole, especially early in the morning or late in the evening, when these insects are in a sort of torpor. To drive whole swarms of little grasshoppers-of which the fish are particularly fond-into the water, it will suffice to walk past the willows and brush against them at noon time, when these insects have retired from the neighboring meadows into the shade of the willows. The willows also furnish shade, which is very beneficial for the trout and shrimps, keep the water cooler, make the banks firmer, and may eventually yield a revenue by selling their branches to basket-makers. In places where the ditches widen out considerably, boards painted white and laid on posts fixed in the bottom of the ditch will keep the water cool and furnish very desirable resting-places for the fish. It may likewise be recommended in the beginning, especially in erawfish-eulture, to dig horizontal holes in the sides of the ditches and thereby to furnish still more hiding-places.

During the first year the above-mentioned crustaceans, insects, etc., will furnish sufficient food for the young salmon; but if they are to grow rapidly, and if the culture is to be made remunerative, they should, during the second and third year, be fed with a constantly increasing quantity of small fish, at regular intervals. To raise these fish separately, one or more sunny, shallow, and warm ponds, stocked with the rapidly increasing erucian carp (Carassius vulgaris), will answer the purpose. If the young crucian carp are to develop rapidly the spawners should be removed, either by catehing them with nets just after the spawn has been deposited, or by draining the pond if the young fish have already been hatched. Crustaceans bred in liquid manure may be raised as food for them on the edges of the ponds. The young crucian carp are caught with nets whenever needed, and are given to the salmonoids alive, but to the crawfish and shrimps dead and chopped fine.

By an establishment like the one described the water of a stream will, without proving an injury to establishments of any kind farther down the stream, yield at least three times more than it would otherwise. The remunerative character of the rational eulture of salmonoids or erawfish, especially in the neighborhood of large cities, will make it profitable to start such establishments on good pieces of ground (e. g., meadows). By the soil which is dug out the surrounding meadow will be improved (rejuvenated), by the ditehes and channels it may possibly also be irrigated in part, and its productiveness will be increased.

Difficult as the management of such an establishment may appear at the first moment, it is not so in reality, if a systematic plan calculated for a number of years is followed. It would give me great pleasure if this article would contribute its share in iuducing people to start many well-paying salmonoid and crawfish establishments. 


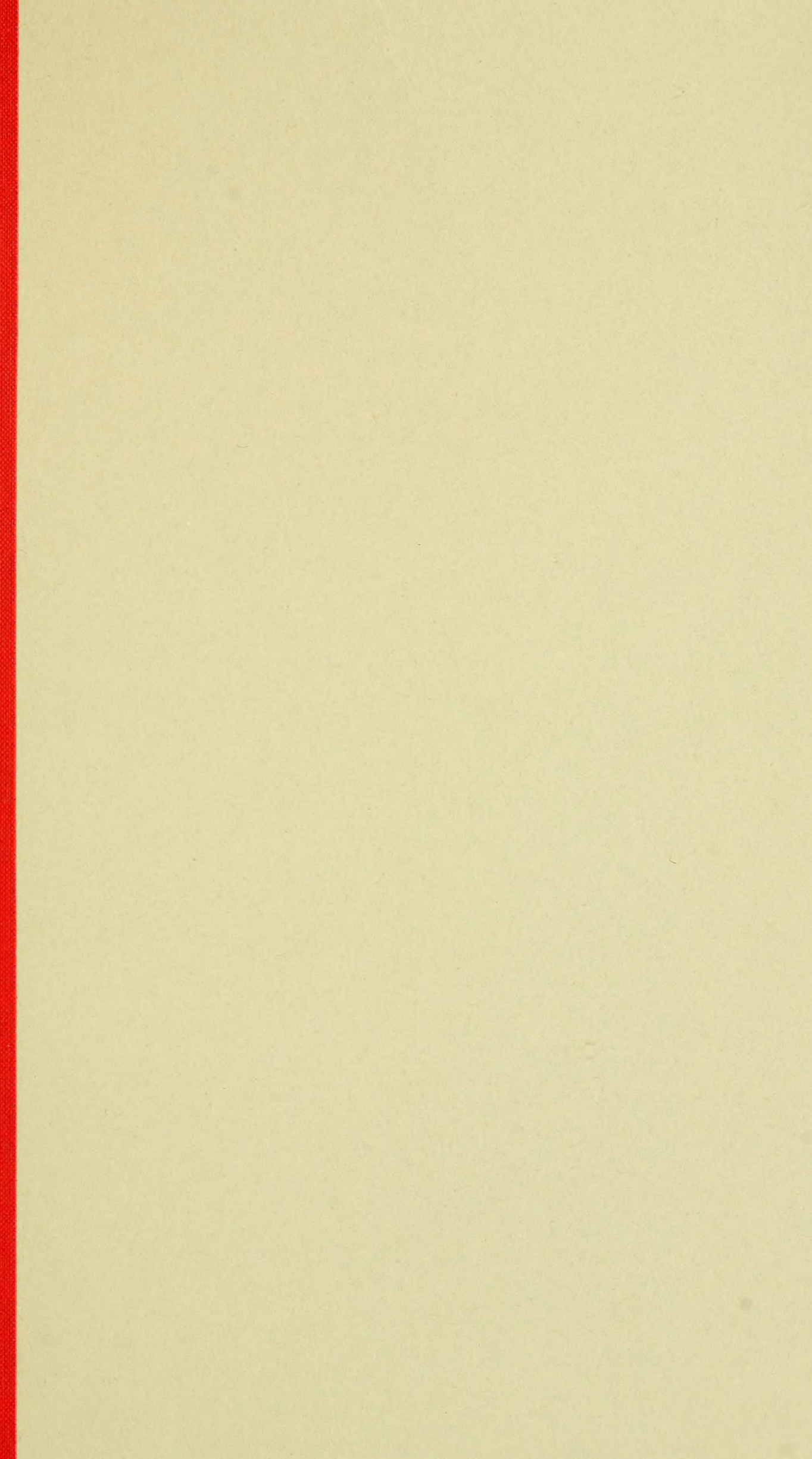


